\section{La actividad editorial intramuros como práctica cultural de extensión universitaria}

María José Rubin

Equipo de Coordinación del Programa

de Extensión en Cárceles

Universidad de Buenos Aires, Argentina

rubinmariajose@gmail.com

(iD) orcid.org/0000-0002-1343-5121
Cultura(s) en clave de extensión universitaria / Intervenciones
RECEPCIÓN: 28/06/19

ACEPTACIÓN FINAL: 30/08/19

\section{Resumen}

El presente artículo reflexiona en torno a la actividad del Taller Colectivo de Edición (TCE) como curso de extensión de la Facultad de Filosofía y Letras de la UBA y a su especificidad en tanto instancia de trabajo que pone en juego herramientas del quehacer editorial. Esta propuesta pedagógica que se desarrolla desde 2008 busca habilitar un espacio y una práctica que recupere las experiencias, los saberes y la capacidad crítica de los y las talleristas para constituirse en un colectivo de trabajo con miras a la publicación de una revista. A partir de la labor realizada por el TCE, el presente trabajo se propone recuperar la actividad editorial en el marco de la extensión universitaria y los productos que de ella resultan como fuente para la construcción de una memoria respecto de la práctica cultural intramuros que se en articulación con la universidad. Esto, a su vez, plantea la necesidad de redefinir la concepción de Edición tradicional en el marco de su trabajo en territorio desde la perspectiva de la extensión universitaria.

Palabras clave: Taller colectivo de edición, educación en cárceles, extensión universitaria.
Prison editing: a cultural practice in university extension

\section{Abstract}

This article reflects on the activity of the Taller Colectivo de Edición (TCE) as an extension course of the Faculty of Philosophy and Letters of the UBA and its specificity as a work instance that brings into play tools of editorial work. This pedagogical proposal that has been developed since 2008 seeks to enable a space and a practice that will recover the experiences, knowledge and critical capacity of the workshops to become a working group with a view to publishing a magazine. Based on the work carried out by the TCE, the present work intends to recover the editorial activity within the framework of the university extension and the products that result from it as a source for the construction of a memory regarding the intramural cultural practice that is in articulation with the university. This, in turn, raises the need to redefine the concept of Traditional Edition within the framework of its work in territory from the perspective of university extension.

Keywords: Collective edition workshop, education in jails, university extension.
A atividade editorial prisional como prática cultural de extensão universitária

\section{Resumo}

Este artigo reflete sobre a atividade da Taller Colectivo de Edición (TCE) como um curso de extensão da Faculdade de Filosofia e Letras da UBA e sua especificidade como instância de trabalho que traz ferramentas de trabalho editorial. Esta proposta pedagógica que vem sendo desenvolvida desde 2008 busca possibilitar um espaço e uma prática que recuperem as experiências, o conhecimento e a capacidade crítica das oficinas para se constituírem em um grupo de trabalho com vistas à publicação de uma revista. Com base no trabalho realizado pelo TCE, o presente trabalho pretende recuperar a atividade editorial no âmbito da extensão universitária e os produtos que dela decorrem como fonte para a construção de uma memória referente à prática cultural intramural que está em articulação com a universidade. Isto, por sua vez, levanta a necessidade de redefinir o conceito de Edição Tradicional dentro da estrutura de seu trabalho no território a partir da perspectiva de extensão universitária.

Palavras-chave: in Workshop de edição coletiva, educação em jail, extensão universitária.

Para citación de este artículo: Rubin, M.J. (2019). La actividad editorial intramuros como práctica cultural de extensión universitaria. +E: Revista de Extensión Universitaria, 9(11), 196-214. doi: 10.14409/extension.v9i11.Jul-Dic.8723. 


\section{Introducción}

El Taller Colectivo de Edición es un colectivo editor que produce revistas bianualmente en los centros universitarios del Complejo Penitenciario Federal de la CABA, el Complejo Penitenciario Federal I y el Complejo Penitenciario Federal IV de Ezeiza. En términos institucionales, se dicta como un curso extracurricular de frecuencia semanal en el marco del Programa de Extensión en Cárceles (PEC), dependiente de la Secretaría de Extensión Universitaria y Bienestar Estudiantil (SEUBE) de la Facultad de Filosofía y Letras (FFyL) de la Universidad de Buenos Aires (UBA). El producto editorial, que es también un objeto cargado de un prestigio social y vía para la legitimación cultural, funciona en este contexto como soporte de una memoria del colectivo. Así, posibilita la permanencia y reconfiguración en el tiempo de una identidad que trasciende a los sujetos individuales que, por la propia lógica y las condiciones del contexto, no pueden prever ni mucho menos garantizar una participación sostenida a largo plazo.

Por el modo en que concebimos esta práctica y por la ética de trabajo que proponemos desde el plantel docente, consideramos que las revistas publicadas pueden abordarse como una construcción colectiva de la universidad con los actores que configuran el territorio donde desarrollamos la actividad. Estas revistas guardan las marcas de los encuentros entre estudiantes y docentes universitarios e integrantes de una población que, conjuntamente, generan lógicas específicas que integran los saberes técnicos y experienciales de sus participantes para construir conocimiento sobre la base de las inquietudes y las problemáticas del territorio, sus soluciones y reformulaciones. Estudiar estas prácticas supone atender a los modos en que se establecen los vínculos pedagógicos en el colectivo, enmarcado en propuestas formativas que construyen "territorios pedagógicos" en contextos de encierro (Bustelo, 2017), en constante tensión con la lógica penitenciaria.

Por otra parte, interesa rastrear también los modos en que la práctica en territorio regresa a los estudios sobre la actividad y el campo editorial, cómo lo reconfiguran y hacen necesaria la reflexión en torno a las definiciones tradicionales de qué es editar. La pregunta que guiará este trabajo es, entonces: ¿qué entendemos por edición en contextos de encierro y de qué manera estas prácticas nos permiten reposicionarnos respecto de la noción de actividad y producto editorial más visitada por los estudios del campo?

Lejos de las lógicas comerciales constitutivas de la industria, resulta fructífero abordar la labor editorial intramuros a la luz de fenómenos editoriales como el de las revistas culturales en Argentina, entendidas en tanto emprendimientos intelectuales colectivos como respuesta necesaria a una coyuntura política o estética (Sarlo, 1992; Beigel, 2003; Prislei, 2015), y consideradas como "documentos de cultura, en términos de Benjamin, porque permiten disecar un determinado estado del campo intelectual" (Beigel, 2003:113). Asimismo, es fructífero ponerlas en relación con el formato tanto material como de distribución del fanzine, privilegiado por movimientos políticos (Alamos, 2018) y culturales (Schmied, 2018), y caracterizado por "sus facetas identitarias, contraculturales y contrahegemónicas respecto a los medios masivos del establishment comunicacional" (Cosso y Giori, 2015:8).

Con el objetivo de abordar estas perspectivas, el presente artículo se organizará en siete apartados que podrían distinguirse como dos grandes partes: primero se ofrecerá una aproximación sucinta al taller que dará cuenta de su "Historia y marco institucional". A continuación, se expondrán las particularidades propias de "El Taller Colectivo de Edición como curso extracurricular y su trabajo en el aula". Luego se abordarán los modos de "Editar según 
lógicas horizontales de trabajo: desafíos y potencialidades" de la actividad desarrollada por el taller. Seguidamente, se visitará la experiencia de "EI TCE como materia curricular: un nuevo desafío para nuestras prácticas". A partir de aquí, en lo que podríamos considerar una segunda parte del artículo, se propondrá el desafío de "Repensar la edición: cómo el trabajo intramuros interpela las definiciones tradicionales". Luego se describirán las implicancias de la articulación entre el taller y la cátedra de Pasantía Pública de la carrera de Edición en un apartado llamado "De la universidad a la cárcel, de la cárcel a la universidad". Finalmente, se ofrecerán las "notas para una definición" de la edición en contextos de encierro partiendo de las especificidades expuestas a lo largo del artículo.

Interesa señalar que, a continuación, se nombrará como "talleristas" a quienes asisten al taller e integran el colectivo editorial. Esto incluirá a las personas que se inscriben como estudiantes a la propuesta de extensión de la universidad tanto como a quienes cumplimos un rol de coordinación. Si bien no ignoramos el lugar diferencial que ocupamos en tanto docentes que habilitan y dan marco al espacio pedagógico, también trabajamos conjuntamente en procura de establecer un pie de equidad que permita la circulación de la palabra y, con ella, la socialización de la toma de las decisiones que constituyen la labor editorial. Así, "talleristas" suele designar al colectivo editorial conformado por todas las personas que participan, mediante distintas tareas y roles, del proceso de edición de la revista.

\section{Historia y marco institucional}

El Taller Colectivo de Edición (TCE) es un curso extracurricular que se desarrolla actualmente en tres penales federales de la Argentina, en el marco del Programa de Extensión en Cárceles (PEC) dependiente de la Secretaría de Extensión Universitaria y Bienestar Estudiantil (SEUBE) de la Facultad de Filosofía y Letras (FFyL) de la Universidad de Buenos Aires (UBA). En este contexto, desde 2008, el TCE edita publicaciones periódicas como resultado de su labor cuatrimestral en centros universitarios intramuros que la UBA sostiene a partir de su Programa UBA XXII de educación en cárceles. Desde sus orígenes como iniciativa de la carrera de Edición (FFyL, UBA), el TCE continúa nutriéndose de su vínculo con esta y otras carreras de la Facultad, especialmente el Profesorado y la Licenciatura en Letras y en Ciencias de la Educación, así como de sus lazos con otras propuestas educativas que forman parte de los centros universitarios en los que se dicta y del contacto con organizaciones de liberados y otras que se desempeñan en contextos de encierro 0 , de forma más amplia, que trabajan por el derecho a la educación, la comunicación y en contra de la discriminación.

EI TCE también se constituye como un territorio de indagación teórica en el marco proyectos de investigación UBACyT sobre escritura y contextos de encierro, radicados en el Instituto de Filología y Literatura Hispánica "Doctor A. Alonso" de la FFyL, UBA.

A partir de su intervención cuatrimestral en la programación extracurricular del Centro Universitario Devoto (CUD), el Centro Universitario Ezeiza (CUE) y el Centro de Estudiantes Universitarios de Ezeiza (CEUE), actualmente el TCE publica tres revistas cuatrimestrales bajo el sello de la Editorial de la Facultad de Filosofía y Letras (EFFyL). Los temas y contenidos de estas publicaciones se deciden y producen en el marco del taller y se imprimen en la Oficina de Publicaciones de Filosofía y Letras (OPFyL). En 2014, la Legislatura de la 
Ciudad Autónoma de Buenos Aires las declaró de "Interés para la Promoción y Defensa de los Derechos Humanos".

Los antecedentes del TCE datan de 2008 y se iniciaron en el CUD, el Centro Universitario del Complejo Penitenciario n. ${ }^{\circ} 2$ ubicado en el barrio de Devoto, Ciudad Autónoma de Buenos Aires. Su primer impulsor fue Rubén Calmels, en ese entonces docente de Publicaciones Periódicas en la carrera de Edición (FFyL, UBA) y subsecretario de Publicaciones de la misma casa de estudios. Desde 2010, la actividad continuó a cargo de dos editores, en aquel momento alumnos de la carrera, Tomás Manoukian y Alejandro Schmied. Como resultado de esta intervención nació el Taller Colectivo de Edición y, con él, la revista La Resistencia, que en julio de 2019 presentó su número 20. Desde 2013, el TCE también participa de la propuesta extracurricular del CEUE, en el Complejo Penitenciario Federal I de la ciudad de Ezeiza. Durante el primer cuatrimestre de 2019 se realizó en este espacio el número 13 de Los Monstruos Tienen Miedo, la segunda revista del taller. Este año fue también el momento de inauguración de un nuevo espacio, cuando el taller comenzó a realizarse en el Complejo Penitenciario IV de Ezeiza, donde se fundó la revista Desatadas, que en julio presentó su primera edición.

Las tres publicaciones están disponibles de forma gratuita en formato impreso y en línea a través de nuestro blog, tallercolectivoedicion.wordpress.com, y en la página web de las revistas de extensión de la Facultad, http://seube.filo.uba.ar/banner/revistas-de-extensi\%C3\%B3n.

\section{El Taller Colectivo de Edición como curso extracurricular y su trabajo en el aula}

Como curso extracurricular, el TCE se desarrolla semanal o quincenalmente en cada centro universitario, en encuentros que se extienden de dos a tres horas y están disponibles, previa inscripción, a toda la población de los penales donde se dicta -no sin obstáculos o salvedades habituales en este contexto- con menores restricciones que materias del Ciclo Básico Común (CBC) de la UBA o, desde luego, en comparación con materias de las carreras que tienen presencia en los penales. Esto supone que el TCE es una puerta de ingreso al ámbito universitario: muchos de los estudiantes que inician su actividad en este y otros talleres conocen el espacio y sus modos diversos de funcionamiento respecto de la lógica carcelaria y a raíz de esta interacción es que se informan sobre las propuestas de Educación Superior disponibles y se interesan por emprender sus estudios universitarios.

En su gran mayoría, el estudiantado de estos centros universitarios no forma parte del grupo privilegiado de "los herederos", en términos de Bourdieu y Passeron (2003), sino que se trata de estudiantes universitarios con una génesis paradójica: como una vuelta de tuerca adicional al caso de las clases bajas a las que refieren los autores citados, el "origen social" de estos sujetos, "el hábitat y el tipo de vida cotidiano que le está asociado" (2003:26), resultaba tan desfavorecedor para el acceso a la universidad que, finalmente, terminó conduciendo a ella por una vía imprevista. Estos sujetos han accedido a la universidad a partir de su condición de presidiarios y, en la gran mayoría de los casos, se desprende de sus biografías que, de haber permanecido en el medio libre, seguramente no hubieran completado siquiera el nivel de enseñanza obligatorio.

Como consecuencia de ello, además de un trabajo de "alfabetización académica", también hay un fuerte acompañamiento en cuanto a la "socialización académica": el aprendizaje en cuanto a los comportamientos y tipos de relaciones que allí se establecen (de los géneros 
discursivos propios del nuevo ámbito, en suma) es parte fundamental de la experiencia de acceso a la universidad. Este procedimiento tiene la particularidad de que es acompañado tanto por los docentes que, especialmente en el caso de los extracurriculares, tenemos plena conciencia de que los estudiantes primerizos incursionan en un espacio que les resulta muy ajeno en un primer momento, sino también por otros estudiantes que, en los talleres, conviven con los recién llegados. Así, estudiantes con varios años de trayectoria académica guían y asisten a los no iniciados para que puedan comenzar a desempeñarse en el espacio, tanto en términos infraestructurales (dónde se encuentra la biblioteca, dónde el área de asesoría jurídica, cómo se accede a la sala de computación) como administrativos (cómo inscribirse a una carrera, qué documentación presentar y cómo solicitarla), pero también en la relación con el propio SPF (cómo afrontar irregularidades en el acceso al espacio desde los pabellones, cómo dirigirse a los empleados del servicio para lograr el acceso y no una sanción, cómo informar a los docentes si no logran resolver estos inconvenientes). Esta socialización, sin dudas, es clave para la permanencia en el espacio: en términos materiales, el acceso al espacio de centro universitario es una conquista diaria.

El funcionamiento del TCE como taller extracurricular abierto a toda la población del penal también implica que el aula donde nos reunimos acoge muchas veces a personas con diversas trayectorias educativas, alojadas en una misma institución pero en condiciones muy disímiles según el módulo o pabellón en el que se encuentren y con historias previas que se enmarcan en contextos socioculturales, geográficos y generacionales muy diferentes. Todos y todas constituimos bajo el nombre de Taller Colectivo de Edición el equipo de trabajo que llevará a término la publicación de un nuevo número de la revista en cuestión.

Dado que cada nuevo cuatrimestre los y las integrantes de este colectivo varían (en función de los egresos, traslados o superposición de otras actividades que surgen con el correr del tiempo), la primera tarea que desarrollamos es, en cierto sentido, nuestro propio acto fundacional: nos constituimos en colectivo editor en la misma medida en que comenzamos a transitar las primeras conversaciones acerca de quiénes somos individualmente y cuál es la labor que nos convoca en el marco del taller. Así, por sobre una mesa con números anteriores de la revista (y de las otras que se realizan en los demás penales) iniciamos un intercambio de saberes que incluyen desde los nombres de cada tallerista (es decir, de cada asistente al taller y de quienes sostenemos un rol de coordinación pedagógica y profesional) hasta los temas de interés más relevantes y los caminos del circuito editorial que recorreremos durante el cuatrimestre.

De esta manera, la propia historia de las revistas funciona como un hilo conductor que permite construir una identidad colectiva capaz de reconocerse como parte de una tradición. El producto editorial como objeto cargado de un prestigio social y vía para la legitimación cultural funciona en este contexto como soporte de una memoria del colectivo y posibilita la permanencia y reconfiguración en el tiempo de una identidad que trasciende a los sujetos individuales del momento presente que, por la propia lógica y las condiciones de dicho contexto, no pueden prever ni mucho menos garantizar una participación sostenida a largo plazo.

Este momento inicial implica, por lo tanto, reconocer la línea editorial del proyecto, que responde, en primer lugar, a una voluntad colectiva que no solo se traduce en una lógica de trabajo horizontal —lo cual se abordará con mayor detalle en el siguiente apartado- sino también en la construcción de una voz plural que permita plasmar en la revista un nosotros 
desde el cual interpelar a lectores y lectoras. Esto supone dejar de lado la lógica individual con la que los grandes medios suelen tratar los casos resonantes de quienes violan la ley -a través de un prontuario que se difunde solo para hacer público el ejercicio o el merecimiento de una condena- $y$ hacerle frente al discurso generalizador y estigmatizante que generan en torno de la población penal en las pocas líneas que les dedican. Es en estos términos que concebimos las revistas editadas por el TCE como medios contrahegemónicos, en tanto se oponen a los modos habituales de abordar y construir estereotípicamente la figura de las personas privadas de su libertad ambulatoria y proponen, en cambio, una instancia desde la cual estas personas puedan tomar la palabra y decirse de un modo diferente al que son dichas por las voces más resonantes.

En este sentido, también consideramos que es fundamental pensar al TCE como propuesta de extensión universitaria y entablar un diálogo con los debates que se han desarrollado en los últimos años en este marco. Entender el taller como un espacio de trabajo horizontal implica superar la "lógica voluntarista" (Petz, 2015:3) de la que alerta la actual Secretaría de Extensión Universitaria y Bienestar Estudiantil (FFyL, UBA) en su diagnóstico crítico sobre el ámbito de extensión, atendiendo al lugar desde el cual participamos del TCE quienes asistimos como docentes e integrantes de un equipo de coordinación técnica y pedagógica. Al respecto, Ana Lucía Salgado (2016) señala que la labor a la que nos dedicamos "no es dar voz, no es un acto asimétrico de caridad. Es hacer silencio, para que el otro pueda hablar" (p. 124).

Compartimos la noción expuesta por Petz (2015) en cuanto a que es fundamental para las prácticas desarrolladas en el ámbito de la extensión universitaria

intentar el esfuerzo de hacer consciente el marco teórico que se encuentra detrás de nuestros programas de trabajo e intervenciones. Transparentar, poner sobre la mesa los supuestos, las concepciones acerca de los sujetos con los que trabajamos, es parte del quehacer, ya que son los que orientan nuestras formas de proceder. (p. 3)

En efecto, el modo en que logramos (o proponemos) constituirnos en un equipo de trabajo colectivo es mediante el intercambio constante de información: aquella propia del hacer técnico editorial y también las bases teóricas e ideológicas sobre las cuales concebimos nuestra práctica. Es por eso que las primeras ideas para cada nueva revista no solo atañen a los temas de interés para tratar sino, de manera más amplia, a toda la escena enunciativa que se configura a partir del ejercicio de la palabra con miras a la comunicación a través de un medio gráfico. No se trata solamente de pensar qué deberíamos publicar sino, y por sobre todo, de preguntarnos constantemente a lo largo del cuatrimestre qué imagen colectiva queremos inscribir como enunciador en la revista, cómo imaginamos al lectorado que la recibirá y de qué forma queremos que se acerque y se reconozca en ella como enunciatario.

Con este horizonte como guía, la primera parte del cuatrimestre se destina a la producción, recepción o encargo de materiales escritos e ilustraciones. Cada uno de los textos y dibujos recibidos se comparte durante el tiempo de trabajo en el aula y se debate para definir su inclusión, con o sin modificaciones, en el índice de la revista. Todo el material se retira de los penales en manos de los y las docentes que coordinan el taller y se digitalizan para su posterior corrección y diagramación. Participan de esta instancia estudiantes avanzados de la carrera de Edición, cuya labor se considerará en un apartado especial más adelante. 
A lo largo del cuatrimestre, el índice va tomando forma a partir de los materiales recibidos, que pueden ser espontáneos — cuando el o la autora decide acercar su producción independientemente de los ejes temáticos definidos para la edición en curso- o responder a la demanda del colectivo, que encarga determinadas producciones a sus propios integrantes o a escritores e ilustradores externos (alojados o no en el penal) dispuestos a colaborar con la revista. En paralelo con este proceso, se identifican los elementos recibidos con las secciones habituales del medio, se nombran las secciones especiales de cada número y se jerarquizan los temas en función de su importancia para organizarlos de forma aproximada en los lugares clave de la revista: tapa, contratapa, página 1, páginas centrales, entre otras. Pasada la fecha de cierre para la recepción de materiales, que se estipula a inicios del cuatrimestre en función del calendario vigente y se recuerda en cada encuentro, el colectivo editor procede a la confección de un paginado estimado. Esta herramienta se elabora con el índice de textos e imágenes recibidos y permite prever de cuántas páginas será la revista, cuántas páginas ocupará cada texto y en qué número o números de página comenzará y terminará.

A partir de ese paginado se diagrama la revista mediante un programa informático de diseño. Si bien esta instancia se realiza principalmente por fuera del trabajo en el aula, debido a las limitaciones tecnológicas propias del contexto, se comparten en este espacio los avances parciales $\mathrm{y}$, en ocasiones, se diseñan artesanalmente algunas páginas importantes y se elaboran figuras gráficas mediante la técnica del collage. Los últimos encuentros de cada cuatrimestre se destinan a recabar la información que se publica en la tapa y en las primeras páginas de cada revista: los temas destacados, los nombres de los colaboradores, las entradas del índice definitivo, los agradecimientos y menciones especiales. La revista impresa llega junto con los diplomas en el acto de fin de cuatrimestre y desde ese momento se distribuye en el interior del penal - a cargo de quienes allí residen-, sale en manos de conocidos y familiares, y se presenta en eventos académicos y propuestas de formación llevadas adelante en diversas instituciones educativas por los y las integrantes del PEC.

\section{Editar según lógicas horizontales de trabajo: desafíos y potencialidades}

EI TCE nombra un curso extracurricular tanto como un colectivo editor. En sus orígenes, esta propuesta se fundó en el encuentro de aquellos coordinadores estudiantes de Edición con los talleristas inscriptos, también estudiantes, al curso de Edición del CUD. La labor que emprendieron en conjunto se vio enriquecida por las inquietudes que los coordinadores compartían en su militancia estudiantil en la universidad, donde integraban por aquel entonces la agrupación Pasajeros de Edición. Es así que, desde sus inicios, los equipos de coordinación reactualizan en cada nuevo cuatrimestre la vocación de realizar una práctica horizontal que permita a los compañeros inscritos en el curso tanto como a las coordinadoras (hoy, todas mujeres) participar en un pie de equidad de la formulación y confección de la revista, sin por ello dejar de atender a los límites de estas posibilidades.

La lógica punitiva e infantilizadora según la cual funciona la institución penitenciaria que nos enmarca —la "pedagogía de la irresponsabilidad", como la define Rita Segato (2003)— se enfrenta de manera directa con nuestra práctica y es la que le otorga toda su potencia emancipadora.

Las aulas, bibliotecas y espacios educativos dentro de penales e instituciones de encierro suelen ser pequeños sitios de libertad, donde se construyen relaciones distintas a las 
que impone la cárcel (...). Su contracara es la lógica del disciplinamiento y la violencia institucional que amenaza todo el tiempo con irrumpir y que necesariamente atraviesa los argumentos y narraciones en el ámbito educativo. (Parchuc, 2015:17)

Establecer un modo de trabajo horizontal y colectivo en este marco es un desafío que se renueva a cada semana; a veces, podría decirse que a cada instante. No se trata, dicho burdamente, de "vigilar" el funcionamiento de un grupo; eso, en un sentido, se parecería bastante a imponer una lógica de forma vertical y no rompería verdaderamente con las dinámicas jerárquicas arbitrarias que buscamos desarticular. En cambio, se trata de una reflexión constante y explícita, compartida, que no solo "evalúe" formas de trabajo sino que permita a todos y todas quienes participamos del taller tener voz y voto respecto de cualquier instancia de decisión que se presente y sea puesta a discusión. En efecto, cómo se presenta, cómo emerge, cómo el colectivo decide qué está sujeto a decisión, a discusión, es también un ejercicio que constituye una redefinición de los límites de "lo enunciable", que es en sí misma una práctica emancipadora. Dice Juan Pablo Parchuc (2015), director del Programa de Extensión en Cárceles y Coordinador de la Carrera de Letras en UBA XXII:

Las situaciones o escenas en las que las personas privadas de libertad y liberadas hablan, con o sin el manto de la condena previa, producen un límite o borde simbólico en el campo de lo enunciable, que pone en juego e interpela nuestra capacidad de oír, pero sobre todo nuestra disposición para escuchar. (p. 27)

Parte necesaria de lo enunciable en el marco del TCE para que podamos constituir un verdadero colectivo horizontal son los límites que cada uno y una de sus integrantes afrontamos en cuanto a las tareas que involucra la producción de una revista. Existen los límites propios de las capacidades y los saberes disponibles, dictados por el conocimiento de cada participante y también por el contexto carcelario, así como los límites autoimpuestos de quienes, en todo momento, tratamos de aportar nuestro trabajo desde una posición que no se perciba como jerarquizada o de autoridad en tanto esto no sea necesario o explícitamente justificado.

El trabajo de edición que hacemos sobre esos materiales, nosotros los editores desde afuera (docentes y pasantes), apunta a ser solo técnico-administrativo y que las decisiones conceptuales se tomen desde el colectivo editorial. Es decir, realizamos aquello que no pueden resolver los compañeros desde el encierro, por las limitaciones del contexto 0 por falta de saberes técnicos. (Salgado:124)

El primer obstáculo al que nos enfrentamos en el afán de preservar una dinámica de trabajo horizontal toma la forma de una paradoja: ¿quién y cómo debe garantizarla? En 2013, los coordinadores y las coordinadoras del taller lo planteaban en estos términos: "El problema es cómo construir en conjunto cuando la iniciativa (original) es de los que vamos de afuera y a la vez cómo hacer flexible la propuesta sin perder participación" (Gaudio et al., 2013). A esta pregunta proponían varias respuestas. Por un lado, apoyados en un texto de Jo Freeman (1973) leído en el marco del taller, se convocaba a prevenirse del "riesgo de reproducir, sin explicitar, formas organizativas 'tradicionales', piramidales (...) difundiendo la información que hace posible la toma de decisiones". Un primer movimiento fundante y sin duda revolucionario en un contexto en el que retacear información es un arma fuerte de 
disciplinamiento y control, que deja a los sujetos en una "condición infantil, minusválida, [en la que] es imposible ser responsable" (Segato, 2013).

Ante esto, es imprescindible que no solo mantengamos una reflexión constante respecto de nuestra propia práctica en el marco del taller sino, y por sobre todo, que hagamos explícita y colectiva dicha reflexión. Nos hacemos eco de estas palabras: "Nuestra verdadera operación pedagógica, si la hay, es defender la propuesta de un espacio horizontal donde dejamos de ser profesores para pasar a ser integrantes de un colectivo editor" (Gaudio et al., 2013:4).

Ahora bien, no deja de resultar innegable que, ante los ojos de quienes nos reciben en el aula del CUD, los talleristas que ingresamos desde la calle, sin mediar pabellón, portamos la investidura que cada semana nos recuerdan los mismos guardias al grito de "ingresa docente" y que los propios compañeros reproducen, en sentido inverso, cuando nos despiden en la reja: "sale docente". Ingresamos y salimos docentes, cada vez, y entre uno y otro voceo nos esforzamos por convertirnos en talleristas. En nuestro auxilio llegan las revistas como proyecto en común, como horizonte que nos convoca y que nos interpela en igual medida. "La materialidad del libro pone a dos espíritus a una distancia que los mantiene como iguales", decía Rancière (2013[1987]:21) pensando en algo parecido aunque diferente. Podemos concordar con él, sin embargo, cuando describe que:

En la situación experimental creada por Jacotot, el alumno estaba vinculado a una voluntad, la de Jacotot, y a una inteligencia, la del libro, enteramente distintas. Se llamará emancipación a la diferencia conocida y mantenida de las dos relaciones, al acto de una inteligencia que solo obedece a sí misma, aunque la voluntad obedezca a otra voluntad. (pp. 8-9)

En el caso del TCE, también hay juego de voluntades, hay negociación, hay unos históricos que pueden presentar el taller ( $y$ el Taller) a los recién llegados, hay pedidos y demandas y negativas ante ellos. Existen, desde ya, voluntades colectivas que se enfrentan entre sí. Lo que no hay, o es nuestro propósito que no haya, es jerarquización de inteligencias fundada en la diferencia de saberes, capacidades o incluso deseos respecto de los modos de participar en la confección de la revista.

\section{EI TCE como materia curricular: un nuevo desafío para nuestras prácticas}

En el año 2016, el ideal regulatorio de conformar un colectivo editor horizontal se enfrentó al gran desafío de ceñirse a una estructura curricular: como asignatura, Edición de Publicaciones Orientadas a la Comunicación Comunitaria formó parte en dos ocasiones del plan de estudios de la Diplomatura en Gestión Sociocultural para el Desarrollo Comunitario. Este marco curricular fue formulado por el PEC como modo de articular los distintos talleres extracurriculares, lograr un mejor posicionamiento institucional ante el Servicio Penitenciario Federal (SPF) y proporcionar a los estudiantes una alternativa de mayor jerarquía académica que, sin embargo, permanezca accesible a quienes aún no han alcanzado el nivel universitario y que resulte posible finalizar para quienes se encuentran prontos a egresar de la institución penitenciaria.

Por más de diez años habíamos acumulado experiencia de trabajo en contextos de encierro en diversas disciplinas y temáticas como la escritura, los derechos humanos, las políticas contra la discriminación, la educación popular, artes y oficios culturales, y otras formas de intervención desde la cultura y la educación en cárceles; y queríamos hacer un replanteo de 
la intervención para fortalecer los trayectos formativos, articulando los talleres y espacios de formación y producción, y sobre todo pensando el modo en que pudieran contribuir al desarrollo de nuevos proyectos dentro y fuera de la cárcel. (Parchuc y Bustelo, 2018:19)

En este marco, el horizonte de un trabajo verdaderamente colectivo, atento a las particularidades de sus integrantes en el momento de su constitución, que es siempre nuestro eje de acción y reflexión, requirió un nuevo esfuerzo de reflexión y conceptualización de nuestra práctica para ubicarnos en el territorio y retroalimentar las bases de nuestra intervención. Con este encuadre, las docentes, ambas graduadas de la carrera de Edición y en aquel momento coordinadoras del TCE, elaboramos el programa que convertiría al taller extracurricular en materia con cuidado de preservar, en cambio, al taller en tanto colectivo editor.

Abordamos la reflexión sobre la tarea editorial, siempre presente en la práctica del taller, en términos también teóricos, conceptualizando las consideraciones cotidianas en torno a los temas y el tono de textos e imágenes en el trinomio Contenido-Soporte-Público. Casi dos años después, esto se explicaría en los primeros materiales de cátedra que elaboramos para la siguiente cohorte de estudiantes:

Pensar en los lectores es, como se ve en los ejemplos anteriores, pensar en el contenido: qué y cómo publicamos depende siempre de a quién nos dirigimos y cómo queremos presentarnos ante ellos. Esto también involucra el medio por el cual decidimos llegar: si creamos una app para Android o imprimimos una guía telefónica y la llevamos puerta a puerta depende de las necesidades e intereses de nuestro público. Estas tres variables son dependientes entre sí: si modifico una de ellas, las demás se verán afectadas. Un ajuste en los recursos económicos, por ejemplo, que me obligue a elegir si imprimo a coIor o en blanco y negro, necesariamente supondrá repensar los contenidos: ya no podré contar con fotos a color ni con titulares destacados en un tono diferente. Para cautivar a mis lectores y ofrecerles una información clara y legible, tendré que recurrir a otras estrategias de diseño y seleccionar o tratar los contenidos de formas diferentes a las que utilizaba cuando tenía presupuesto para imprimir a color. O bien, imprimir menos ejemplares para conservar el color y llegar a un público más acotado, o dejar de imprimir y llegar solo a un público que se interese por consultar mi publicación en formato digital. (TCE, 2018)

Asimismo, ordenamos el proceso de confección de las revistas que llevamos adelante cada cuatrimestre para distinguir actores y documentos principales, las instancias que componen el camino del original a la revista y sus particularidades. De esta manera, pudimos atender a la gran importancia que tiene para nosotros el proceso de preedición, en tanto que reúne los momentos de confección del índice, escritura de los textos y realización de las ilustraciones, así como toda revisión posible de las políticas y lineamientos editoriales que guían cada número de la revista. Esta instancia que normalmente nos ocupa durante la primera parte del cuatrimestre se presenta como un terreno fértil para la reflexión crítica y la producción y puesta en circulación (en un primer momento, acotada a los talleristas, hasta la publicación del nuevo número) de los saberes que constituyen la trama social del Centro Universitario.

Todos esos saberes son los que permiten sostener las vidas cotidianas de la mayor parte del pueblo, tengan o no certificado de escolaridad. Los saberes que sostienen la vida de 
los pueblos son los saberes que se construyen en la trama social. No los que permiten competir, como nos quieren hacer creer, sino los que permiten construir trama social, centros como este y otras múltiples cosas. (Levy, en Parchuc y Bustelo:48-49)

¿Qué saberes implica ingresar a una nueva esfera de desempeño social en la que prevalecen lógicas relacionales propias de dicho espacio? La segunda cohorte de la Diplomatura, en 2018, volvió a acoger al taller como materia curricular y fue entonces que incorporamos una nueva instancia de trabajo, orientada a guiar la escritura y la autoedición de los textos que integrarían La Resistencia de aquel cuatrimestre. Para ello, optamos por abordar la teoría de los géneros discursivos de Mijaíl Bajtín, según la cual cada esfera de la praxis social se corresponde con "todo un repertorio de géneros discursivos que se diferencia y crece a medida de que se desarrolla y se complica la esfera misma" (Bajtín, 2003:248). Poder desempeñarse en una esfera supone conocer los géneros discursivos que se ponen en juego en las relaciones intersubjetivas que les son propias, es decir, los usos relacionados con contenido temático, estilo y composición o estructuración de los enunciados. Así, desenvolverse en el ámbito universitario requiere del dominio del repertorio de géneros discursivos que le corresponde, lo cual no solo involucra géneros escritos, como la monografía, sino también configuraciones discursivas como el género "clase" o el género "examen final oral", e incluso los estilos apropiados de comunicación entre pares, con los docentes en sus distintas jerarquías, etcétera.

Los géneros discursivos, en tanto permiten encuadrar cualquier enunciado en un horizonte de previsibilidad, son condición de legibilidad y comunicabilidad:

al oír el discurso ajeno, adivinamos su género desde las primeras palabras, calculamos su aproximado volumen (o la extensión aproximada de la totalidad discursiva), su determinada composición, prevemos su final, o sea que desde el principio percibimos la totalidad discursiva que posteriormente se especifica en el proceso del discurso. Si no existieran los géneros discursivos y si no los domináramos, si tuviéramos que irlos creando cada vez dentro del proceso discursivo, libremente y por primera vez cada enunciado, la comunicación discursiva habría sido casi imposible. (Bajtín: 268)

Así, los géneros discursivos funcionan como marco y como condición de la comunicación: no solo ciñen los enunciados a ciertas reglas, sino que al hacerlo les confieren también la posibilidad de significar en una comunicación intersubjetiva.

En la medida en que el sujeto social es capaz de ampliar sus esferas de intervención y especializarse en ellas, también puede formarse en el dominio de géneros discursivos, tanto para extender su repertorio como para profundizar en su dominio. De tal manera, al primer momento del género como restricción del decir sucede un segundo momento de libertad, en que el sujeto puede valerse de su uso para comunicarse de manera más eficiente, clara y conforme a sus objetivos.

Cuanto mejor dominamos los géneros discursivos, tanto más libremente los aprovechamos, tanto mayor es la plenitud y claridad de nuestra personalidad que se refleja en este uso (cuando es necesario), tanto más plástica y ágilmente reproducimos la irrepetible situación de la comunicación verbal; en una palabra, tanto mayor es la perfección con la cual realizamos nuestra libre intención discursiva. (Bajtín:270) 
Así, de manera fundamental para la participación en este ámbito, pero también como herramienta clave de cara a la redacción y publicación de textos en las revistas, el aprendizaje de los géneros discursivos viabiliza el objetivo de entablar un diálogo con lectores potenciales. En tanto géneros literarios o periodísticos, su dominio muchas veces viene dado por lecturas previas, pero también se refuerza con la lectura de números anteriores de las revistas y en el intercambio dentro del propio taller de los materiales producidos durante el mismo cuatrimestre.

Como posibilitadores de la comunicación e intrínsecamente dialógicos, los géneros discursivos suponen siempre una instancia enunciativa en la que tanto enunciador como enunciatario quedan delimitados dentro del propio enunciado. Esto, trasladado al trabajo editorial del colectivo, implica que el posicionamiento autoral ante lectores previstos es uno de los pilares del debate respecto de las estrategias comunicacionales proyectadas para cada número de la revista, en función de la constitución del colectivo durante el cuatrimestre, de las variables en el entorno de las que sus integrantes pueden informar y reflexionar en conjunto, de las circunstancias político-sociales más amplias que nos atraviesan, etc. Lejos de permanecer "dichos" por los discursos sociales habituales acerca de la delincuencia y la marginalidad, el propósito del taller es que participar de una instancia en la que, por escrito pero también como parte de los debates cotidianos, se cuestiona quiénes somos y a quién nos dirigimos, qué imagen queremos proyectar en la revista - es decir, un espacio en el que la dimensión enunciativa es constantemente problematizada - como un primer paso para repensarse también como sujetos.

El resultado fue el número 18 de La Resistencia, una edición que albergó notas específicamente trabajadas desde la perspectiva de los géneros periodísticos propuestos pero que, en rigor, no contempla otros géneros habituales de las publicaciones: cartas, recetas y textos de opinión son las próximas configuraciones enunciativas que nos proponemos abordar con miras a seguir sosteniendo las particularidades y el legado histórico de las revistas sin por ello dejar de lado la reflexión conjunta y crítica respecto de las herramientas que nos restringen y a la vez nos permiten realizar libremente los objetivos comunicacionales del colectivo.

El trabajo con géneros periodísticos en el marco de reuniones que se ajustaban al género clase presentó el desafío renovado de recuperar constantemente la pregunta por qué queremos decir, a quién y como quién. La caracterización y el uso de los géneros periodísticos propuestos, aspectos que constituían una de las unidades temáticas de nuestro programa curricular, por el tiempo que les dedicamos en cada reunión recibieron una atención privilegiada y en muchos casos desplazaron el motor principal del colectivo: traducir en piezas escritas aquellas inquietudes e intereses que emergen en la conversación y el intercambio semanal.

\section{Repensar la edición: cómo el trabajo intramuros interpela las definiciones tradicionales} El trabajo realizado en el marco del TCE nos enfrenta también a la necesidad de redefinir los criterios con los que concebimos la actividad editorial. En primer lugar, para comenzar la charla en el taller, dado que la figura del editor muchas veces es desconocida sin distinción en cualquier nivel socioeducativo:

la profesionalización formal de la labor editorial específica es muy reciente -al menos en nuestra parte del mundo-, y tiene uno de sus hitos fundantes en la creación de nuestra carrera. En su joven historia (recién cumple poco más de veinte años), la generación de 
graduados que hoy somos los docentes tuvimos el desafío y el problema de enfrentarnos a que no se supiera qué éramos y para qué servíamos profesionalmente. (Basso y Salgado, 2015:4)

En el aula solemos partir de las definiciones que propone el glosario del Centro Regional para el Fomento del Libro en América Latina y el Caribe (CERLALC), organismo dependiente de la UNESCO:

Editor: personal natural o jurídica que, por cuenta propia, elige o concibe obras literarias, científicas y en general de cualquier temática y realiza o encarga los procesos industriales para su transformación en libro, cualquiera que sea su soporte, con la finalidad de su publicación y difusión o comunicación. (2008:5)

Las palabras clave son verbos: "elegir", "concebir", "publicar", "difundir", "comunicar". Desde aquí partimos para dar forma a una práctica que, en todo lo demás, se define por la especificidad del colectivo editor: sus inquietudes, intereses y posibilidades en un momento determinado. En cuanto a aquello que producimos, optamos por concebir

la publicación como red de relaciones que puede ser considerada a partir de un objeto material o inmaterial (papel-bits), pero también como un entramado de prácticas, un intercambio social, un texto que nos interpela a partir de los modos en los que nos conectamos socialmente en ese entramado. (Gaudio et. al.:5)

Desde esta perspectiva, el rol del editor se amplía para abarcar no solo los saberes específicos que requiere la labor técnica de producir un bien cultural, sino también toda la dimensión de la circulación social que, en tanto horizonte de la publicación, le es también constitutiva. Esto supone repensar el rol del editor como el de aquel que media entre el autor y el lector, un primer lector privilegiado que tiene la responsabilidad de replantear en cada instancia del taller al destinatario ideal, encarnarlo y presentarle al autor bajo la mejor luz posible sin neutralizar las peculiaridades de su escritura. Decidir si es necesario usar una nota al pie para explicar lo que es un "bagayo" o si conviene reemplazar "bardiarla" por un término aceptado por la Real Academia Española (RAE) es una pregunta por nuestros lectores. Más aún, como nos relató uno de los primeros pasantes de la carrera en graduarse con su trabajo en el TCE, es tarea del colectivo editor reconstruir las implicancias de, por ejemplo, eliminar la "p" de "psicólogo" en una publicación que una parte de nuestros destinatarios podría considerar una "revista de presos" y, por lo tanto, atribuir la letra ausente no a una ajustadísima dinámica de actualización a las novedades que propone la máxima institución normadora de la lengua (que posiblemente ellos mismos desconozcan), sino a un error ortográfico propio de un autor que, en el imaginario social, carga con estigmas asociados por el sentido común ${ }^{1}$ a ciertos miembros "marginales" de la sociedad.

1) El sentido común es también el que impera dentro del sistema penitenciario. Al respecto, Silvia Delfino y Juan Pablo Parchuc señalan, al relatar su propia experiencia: "Fuimos confrontados/as en nuestras prácticas como docentes y militantes por la institución total carcelaria que exhibe y a la vez satura el disciplinamiento a través de mecanismos de seguridad, pero también de arbitrariedad que hacen visibles e intensifican tanto la subordinación en el encierro como los marcos excluyentes y criminalizantes del sentido común" (2017:121). 
Esta capacidad propia de (o deseable en) quienes ejercemos la edición de ver más allá en un contexto específico se logra habitando el taller, participando de las reuniones, siendo parte del colectivo e implicándose en la constante pregunta por quiénes somos y dónde estamos y, en consecuencia, de cara a la revista, a quién nos dirigimos.

\section{De la universidad a la cárcel, de la cárcel a la universidad: los tránsitos de la Pasantía Pública}

Cada cuatrimestre, el TCE recibe pasantes de la carrera de Edición, que suman su colaboración en el marco de sus prácticas para graduarse. Este convenio acerca al CUD y al taller a personas que se encuentran en una instancia final de su formación universitaria como editores y, gracias a esta articulación, de dos a cuatro editores por año concluyen su educación superior y, en muchos casos, realizan su primera experiencia laboral en el taller y para el Taller. Al respecto, expresó una de las pasantes en su informe para la cátedra:

Mi primera experiencia como editora fue una experiencia plena de aprendizaje y de colaboración, construida a partir de un entramado de horizontalidades, a pesar de que los talleristas se empeñaran en llamarnos "profes". Un colectivo de trabajo es justamente eso: dejar de lado verticalidades y jerarquías e intentar dar tanto como se recibe del resto para que, de ese encuentro de individualidades, todos nos veamos beneficiados. (citado en Basso y Salgado, 2014:7)

Que este tipo de reflexión sobre la propia práctica profesional surja en el contexto del TCE nos da una pista de cómo impacta en estos nuevos editores el modo de trabajo que proponemos y la perspectiva que puede otorgar a un profesional en formación, que tiene o tendrá incidencia con su trabajo en el campo de la cultura. No es casual que la propia cátedra de la Pasantía Pública tenga una visión como la que describen dos de sus docentes, Santiago Basso y Ana Lucía Salgado:

En tanto es una instancia final en la carrera y el equipo docente está conformado en su totalidad por graduados de Edición, partimos de la base de que ya somos todos editores -colegas, en definitiva-, y planteamos un formato de paridad en el aula, donde todos tienen voz y pueden aportar sus saberes en igualdad de condiciones. [...] Rehuimos de la idea de que es el docente el que tiene la clave o el saber último: nadie tiene todo el saber de una disciplina y todos tenemos diferentes recorridos y miradas en el campo cultural en el que nos movemos que pueden resultar un aporte valioso a la conversación. (Ibídem: 7)

Ana Lucía también formó parte del TCE: su primera experiencia fue como tutora de un grupo de pasantes y en poco tiempo se convirtió en una de las coordinadoras del espacio. Nos acompañó hasta 2016, luego de cuatro años de una labor comprometida que, además de revistas, dejó como resultado agudas reflexiones que hemos compartido a lo largo de este artículo.

Cynthia Bustelo, coordinadora Pedagógica del PEC, proponía una serie de preguntas en su tesis doctoral que quisiéramos hacer nuestras.

¿Cómo se transforma la cárcel cuando la habitan estas personas? ¿Cómo se transformaron esos territorios, esas experiencias luego del paso de ellos por allí? ¿Qué hizo la cárcel con 
estas personas? ¿Qué hizo la educación con ellos? ¿Qué le hicieron ellos a la educación? ¿Qué nos hacen estos relatos a nosotros como sociedad? (p. 226)

Desde el TCE retomamos estas líneas para pensarnos y pensar las marcas que deja la práctica del taller en quienes la transitan durante los últimos meses de su educación superior.

Durante la pasantía se nos encomendó una tarea específica, podríamos habernos limitado a ella. Es más, salvo la primera o segunda visita, regresar a la cárcel no fue parte de las condiciones laborales. Sin embargo mi compañera y yo sumamos al menos ocho ingresos al CUD. Esta actitud, una decisión grupal, no solo nos fue útil para la tarea desempeñada, sino que nos permitió construirnos frente a ellos como actores presentes, comprometidos y con una participación que seguramente supieron valorar. Cada encuentro fue ocasión para ofrecer nuevas miradas, propuestas y soluciones a los puntos en debate. Pero sobre todo para comentar nuestras ideas que, además de la corrección pedida, pudimos ofrecer y que considero significaron la diferencia. (...) Hicimos lo posible para que (...) sintieran que formamos parte de su proyecto y que nuestro compromiso estuvo a la altura del de ellos. Este tipo de competencia es la que creo le da valor a la figura del "editor". Muchas veces realizamos una tarea particular, pero siempre podremos seguir pensando cómo mejorar el complejo mecanismo de saberes que nos rodea, tanto para el cliente como para nosotros. (citado en Basso y Salgado, 2015:18)

Esto concluyó un pasante que completó su formación universitaria como editor en el TCE. ¿Cuán diferente habría sido su experiencia si hubiese realizado la pasantía en otro ámbito? No podemos saberlo. Pero tenemos la certeza de que hoy el mundo editorial cuenta con un actor que forjó una parte significativa de su experiencia universitaria y laboral en un espacio en el que la horizontalidad de los intercambios entre sus miembros se propone como respuesta subversiva ante la lógica imperante del sistema que pretende, por el contrario, desempoderarlos. Y esto, creemos, no puede sino haber dejado marcas en todos y todas quienes alguna vez pasamos, más o menos tiempo, con mayores o menores grados de responsabilidad (pero no de compromiso) por el TCE.

\section{La edición en contextos de encierro: notas para una definición}

EI TCE se enmarca en términos más amplios en una actividad editorial intramuros que ha mostrado un gran crecimiento en los últimos veinte años (Parchuc, 2018). Los materiales allí producidos configuran un patrimonio hasta ahora no relevado ni debidamente documentado (Bixio et al:35) pese a que representan una oportunidad de poner en circulación saberes y prácticas con potencial transformador sobre la cárcel, el sistema penal y la violencia social e institucional que los sostiene, vinculados a estructuras y condiciones sociales más amplias. Se hace entonces posible y necesario construir una memoria de la intervención cultural de la universidad en contextos de encierro a través de un trabajo de archivo de las publicaciones que considere su relación con las prácticas que les dan origen y a las cuales retroalimentan. La edición nos provee tanto los materiales como una perspectiva privilegiada para su abordaje.

Estudiar las publicaciones realizadas en contextos de encierro desde una perspectiva editorial supone el desafío de incursionar en un campo de estudios que se caracteriza ac- 
tualmente por "un marcado sesgo 'profesionalista', donde el contacto con las herramientas propias del trabajo de indagación académica es escaso" (Broitman, 2013:33). La Edición es abordada mayormente en tanto actividad empresarial (De Sagastizábal y Esteves Fros, 2002), como oficio (McCormack, 2010; Gazzera, 2016) o bien como objeto de políticas estatales destinadas a la promoción de una industria y un mercado editoriales (De Diego, 2014[2006]; Giuliani, 2018).

Sin poner en tela de juicio la pertinencia y necesidad de indagar en estos ámbitos de desempeño de la actividad, el campo editorial tiene pendiente el abordaje de perspectivas que permitan discutir el lugar común que presenta a la Edición (tanto la actividad como sus actores y productos) como objeto "de dos caras" (De Diego, 2010): una material y una cultural. Consideramos que esta contraposición puede desplazarse desde una concepción de la cultura en términos acotados para entenderla, en cambio, de forma más amplia, "como un proceso productivo (material y social)" (Williams, 1977), y a las ideas sociales como "fuerzas materiales" que actúan en el marco de una formación social particular (Hall, 1998:134). Esta perspectiva resulta pertinente para esta investigación, ya que concibe "los problemas de conceptualización y producción de objetos (...) como un punto de conflicto en el que discursos y prácticas [entran] en tensión con sus propias condiciones" (Delfino, 1998:42).

Las publicaciones desarrolladas en contextos de encierro resultan representativas de un modelo de proyecto editorial al que podrían adscribirse fenómenos como, por un lado, el de las revistas culturales en Argentina, entendidas en tanto emprendimientos intelectuales colectivos como respuesta necesaria a una coyuntura política o estética (Sarlo, 1992; Beigel, 2003; Prislei, 2015), y por otro, el formato tanto material como de distribución del fanzine, privilegiado por movimientos políticos (Alamos, 2018) y culturales (Schmied, 2018), y caracterizado por "sus facetas identitarias, contraculturales y contrahegemónicas en cuanto a los medios masivos del establishment comunicacional" (Cosso y Giori, 2015:8).

Sin desestimar la incidencia de las condiciones materiales de producción a las que se ven sujetos los proyectos editoriales en contextos de encierro, como la falta de financiamiento y los recursos técnicos escasos, a la hora de evaluar las características artesanales, la periodicidad variable y la -a menudo- poca continuidad de su producción, estas también responden a las condiciones del trabajo en territorio: los límites y potencialidades propios de estos contextos y el horizonte de una labor de producción artística y de gestión o promoción cultural que procuran no solo ampliar el derecho a la educación y el acceso a los bienes culturales como formas de inclusión e integración social (Parchuc et al., 2018), sino también reducir el daño provocado por el encierro, denunciar la violencia institucional y construir proyectos culturales y comunitarios dentro y fuera de la cárcel (Delfino y Parchuc, 2017:111-112).

Es por esto que su estudio requiere abordar las lógicas vinculares en equipos de trabajo que se constituyen muchas veces en el marco de propuestas formativas, "una forma de estar-en-la-educación" (Chauvin, 2016) que construye "territorios pedagógicos" en contextos de encierro (Bustelo, 2017), alternativos o en contraposición a las estructuras y prácticas penitenciarias. Muchos de estos proyectos se desarrollan en el marco de programas de extensión universitaria que responden a un paradigma anclado en la inclusión, que supone "pensarse [como universidad] desde el lugar de un actor social que interviene en procesos concretos, históricos, en marcos de alianza y negociación que lejos están de una supuesta neutralidad valorativa" (Petz, 2015:1-2). 
Resulta imprescindible, asimismo, revisar el estatuto de la Edición para concebir esta actividad en el marco de procesos de subjetivación colectivos (Parchuc, 2018; Delfino, 1998), teniendo en cuenta la circulación social de la publicación como una de sus dimensiones constitutivas (Rubin, 2017), que vuelve la mirada a la identidad colectiva de quienes enuncian a través de los procesos materiales, simbólicamente inscriptos, de edición. Este esfuerzo busca reconstruir el modo en que los sentidos dados a las experiencias compartidas pueden registrarse en el lenguaje como conjunto de relaciones variables en el que entran en implicación mutua tanto las prácticas como los objetos culturales (Delfino, 1998:34).

No puede resultar ajena, ante esta redefinición, la pregunta por las condiciones de posibilidad de estos proyectos, que requieren de políticas editoriales distintas a las destinadas a la promoción de la industria y el comercio del libro. Para atender a su especificidad, se hace necesario entonces ampliar los horizontes de su campo de investigación, abordando experiencias editoriales que hasta ahora no tienen lugar en sus líneas de indagación, lo cual supondría el mutuo enriquecimiento del campo editorial y de la Edición en contextos de encierro desde la investigación y la transferencia de conocimientos a la sociedad. Esta actividad comporta lógicas de trabajo que integran un paradigma aún no abordado por la escasa pero incipiente investigación en el campo de los así llamados estudios del libro y la edición, ya que se relaciona menos con una actividad industrial y comercial del libro que con la tradición de revistas culturales y fanzines políticos y artísticos. Estos tipos de publicación contraculturales implican unos modos específicos de pensar y también de concretar materialmente una publicación, por lo que sus procesos de trabajo difieren del circuito editorial comercial cuyo equipo técnico-administrativo responde a una estructura vertical y jerárquica. Los fanzines y revistas culturales, en cambio, son portadores de marcas de un hacer colectivo, centrado en una vocación de contacto y comunicación antes que en estrategias comerciales de producción y distribución. En consecuencia, formular políticas que posibiliten y promuevan esta actividad requiere de la reflexión y el estudio de procesos hasta ahora inexplorados en estos términos.

\section{Reflexiones finales}

A partir de lo expuesto anteriormente, podemos retomar la pregunta inicial de este trabajo: ¿qué entendemos por edición en contextos de encierro y de qué modo estas prácticas nos permiten reposicionarnos respecto de la noción de actividad y producto editorial más visitada por los estudios del campo?

Hemos expuesto cómo la labor editorial atañe, en este marco, a la reflexión y el trabajo en torno a la configuración, permanencia y recuperación (a través de la edición, la reproducción técnica y distribución, el archivo) de la identidad cultural de un colectivo y de sus modos de hacerse público. Estos difieren de los que los medios hegemónicos ejercen en relación con las personas privadas de su libertad ambulatoria: en términos individuales, a través de un prontuario que se difunde solo para hacer público el ejercicio de la condena.

Proyectos editoriales como el TCE responden a las condiciones del trabajo en territorio. Esto es, los límites y potencialidades propios de los contextos de encierro y el horizonte de una labor de producción artística y de gestión o promoción cultural que procuran no solo ampliar el derecho a la educación y el acceso a los bienes culturales como formas de inclu- 
sión e integración social (Parchuc et al., 2018), sino también reducir el daño provocado por el encierro, denunciar la violencia institucional y construir proyectos culturales y comunitarios dentro y fuera de la cárcel (Delfino y Parchuc, 2017:111-112).

En tanto construye sus prácticas y aborda su producción en conjunto con los actores del territorio en el que interviene, el proyecto editorial del TCE se desarrolla en el marco de un programa de extensión universitaria que responde a un paradigma anclado en la inclusión. Esto supone, por un lado, "pensarse [como universidad] desde el lugar de un actor social que interviene en procesos concretos, históricos, en marcos de alianza y negociación que lejos están de una supuesta neutralidad valorativa" (Petz:1-2). Por otra parte, el TCE en tanto propuesta extracurricular se encuentra disponible para toda la población de los penales donde se dicta, configurándose en un espacio de encuentro entre personas de diversa procedencia: no solo entre quienes accedemos desde el "afuera" y quienes provienen, en lo inmediato, de celdas o pabellones, sino también entre personas con diversas trayectorias educativas, alojados en una misma institución pero en condiciones muy disímiles y, por sobre todo, con historias previas que pueden enmarcarse en contextos socioculturales, geográficos y generacionales muy diversos. Todo esto tiene su correlato en las revistas, que conservan así la memoria de la intervención cultural de la Universidad en contextos de encierro.

\section{Referencias bibliográficas}

Álamos, R. (2018). La cultura política de los colectivos libertarios latinoamericanos en el Cono Sur. Casos de Chile, Argentina y Uruguay. Tesis de maestría, Universidad de Chile.

Basso, S. y Salgado, A.L. (2014). El rol y la inserción del editor graduado en el campo de la cultura actual: la experiencia de la Pasantía Pública de la Carrera de Edición. En /l Jornadas de Investigación en Edición, Cultura y Comunicación 2014. FILO:UBA.

Bajtín, M. (2003). El problema de los géneros discursivos. En Estética de la creación verbal. Buenos Aires: Siglo Veintiuno.

Beigel, F. (2003). Las revistas culturales como documentos de la historia latinoamericana. En Utopía y praxis latinoamericana, (20), 105-116.

Bixio, B. (2016). Aulas de prisión. En Acin, A. Sentidos políticos de la universidad en la cárcel. UNC.

Bourdieu, P. y Passeron, J.C. (2003). Los herederos. Los estudiantes y la cultura. Buenos Aires: Siglo XXI Editores. Broitman, A. (2013). La investigación desde la perspectiva de los estudiantes de Edición. En Casanovas, I. et al. (Ed.). I Jornadas de Investigación en Edición. Buenos Aires: FFYL-UBA.

Bustelo, C. (2017). Experiencias educativas en contextos de encierro. Tesis de doctorado. FFYL-UBA.

Camarda, A. (2014). Publicaciones en contextos de encierro: publicationmapper.herokuapp.com Chauvin, S. (2016). Taller Colectivo de Edición: inclusión educativa en primera persona (mimeo). Cosso, P. y Giori, P. (2015). Sociabilidades punks y otros marginales. Temperley: Tren en movimiento. De Diego, J. (2010). La otra cara de Jano. Una mirada crítica sobre la edición. Buenos Aires: Ampersand. (2014[2006]). Editores y políticas editoriales en Argentina (1880-2010). Buenos Aires: FCE.

Delfino, S. (1998). Desigualdad y diferencia: retóricas de la identidad en la crítica de la cultura. Doxa, 18. Delfino, S.; Parchuc, J. (2017). Experiencias pedagógicas en contextos de encierro. En Gerbaudo, A. y Tosti, I. (Eds.). Nano-intervenciones con la literatura y otras formas del arte. Santa Fe: FHyC-UNL.

Delfino, S.; Parchuc, J.; Rapisardi, F. (2007). Las acciones contra la discriminación y la represión desde la carrera de Letras. En Espacios de Crítica y Producción, 36, 97-111. FFyL-UBA. 
Freeman, J. (1973). The Tyranny of Structurelessness. The Second Wave. Berkeley: Journal of Sociology, 17. Gaudio, A. et al. (2013). Lógicas horizontales en el encierro. El Taller Colectivo de Edición (mimeo).

Giuliani, A. (2018). El mercado latinoamericano de libros y el primer peronismo. Temperley: Tren en movimiento. Morgade, G.; Arata, N. (2012). Introducción a Dossier Pensar "Filo" como "Humanidades". En Espacios de Crítica y Producción, (48), 4-8. FFyL-UBA.

Parchuc, J. (2014). La Universidad en la cárcel: teoría, debates, acciones. Redes. Revista de Extensión, 1. (2015). La escritura en la cárcel deja marcas. En Wk, 79. Temperley: Tren en Movimiento.

(2018). Escribir en la cárcel. Proyecto UBACyT, programación científica 2018. FFyL-UBA.

Parchuc, J. et al. (2018). Saberes en diálogo. Experiencias de formación en la cárcel. Buenos Aires: PEC-EPISEC.

Petz, I. (2015). Extensión universitaria. En Redes de extensión, 1. FFYL-UBA.

Pittaluga, R. (2006). Notas a la relación entre archivo e historia. En Políticas de la memoria, 6/7. CeDInCl.

Prislei, F. (2015). Polémicas intelectuales, debates políticos. Las revistas culturales en el s. XX. FFyL-UBA.

Rubin, M.J. (2016). Editar a la deriva. En Cultura editorial, 1. Cátedra Libre de Edición y Proyecto Social Boris Spivacow, FFYL-UBA.

(2017). Dinámicas y políticas editoriales en contexto de encierro. Ponencia en el I EITICE. UNICEN.

(2019). Editar colectivamente en la Universidad y en el encierro. En La vida en la cárcel. UNCA.

Salgado, A.L. (2015). Editar [en /desde /contra /a pesar de] la cárcel. En III Jornadas de Investigación en Edición, Cultura y Comunicación 2015. FILO:UBA.

(2016). Editar la cárcel. En Espacios de crítica y producción, (52). FFyL-UBA.

Sarlo, B. (1992). Intelectuales y revistas: razones de una práctica. Cahiers du CRICCAL, (9-10), 9-16.

Schmied, A. (Ed.) (2018). Libro de fanzines. Temperley: Tren en movimiento.

Segato, R. (2003). El sistema penal como pedagogía de la irresponsabilidad y el proyecto "habla preso: el derecho humano a la palabra en la cárcel". Departamento de Antropología, Universidad de Brasilia. Recuperado de: http://lanic.utexas.edu/project/etext/lilas/cpa/spring03/culturaypaz/segato.pdf (consultado el 20/10/2017).

(2007). El color de la cárcel en América Latina Apuntes sobre la colonialidad de la justicia en un continente en desconstrucción. En Nueva sociedad, (208).

TCE (2018). Apunte de cátedra inédito. 